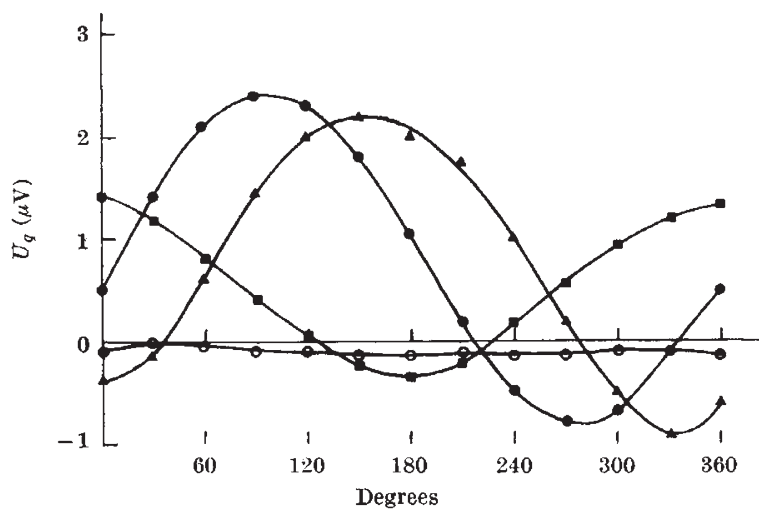

Fig. 2. Bright gold, 0.45 per cent NaCl; $A$ the same, after rubbing electrode surface along $0-180^{\circ}$ diameter; gold, platinized with $150^{\circ}-330^{\circ}$ diameter vertical; $O$ gold, plat

$E_{z}=2.2 \mathrm{mV} / \mathrm{cm}$, frequency $240 \mathrm{c} / \mathrm{s}$.

be so even if the electrode surfaces were perfectly uniform. It appears to be this effect, and not that due to surface asymmetry of the electrodes, which has been observed by Hognestad ${ }^{2}$.

The effect of surface asymmetry can be greatly reduced (as Schwan found) by fitting the electrode in a recess in the insulating wall, thus reducing the potential gradient at the electrode surface. A more detailed account of the experimental work, carried out in connexion with baseline errors in electromagnetic flowmeters for recording blood flow, will be given elsewhere.

$$
\text { D. G. WyatT }
$$

Nuffield Institute for Medical Research, University of Oxford.

${ }^{1}$ Schwan, H. P., Ann. N.Y. Acad. Sci., 65, 1007 (1957).

${ }^{2}$ Hognestad, H, Int. Conference Med. Electronics, Liège (1963).

\section{Laser Excitation of Powdered Solids}

AN understanding of the physical processes which occur when solids are subjected to intense surface heating is important to meteor and re-entry physics and to the physics of comets. These processes have been investi. gated spectroscopically in the laboratory by shock excitation $^{1,2}$, flash photolysis ${ }^{3,4}$ and the impact flash ${ }^{5}$. As shown by Stoicheff ${ }^{6}$, the high temperatures obtainable by using a focused ruby laser beam provide yet another means for the excitation of solids. It is the purpose of this note to report briefly on the spectroscopic investigations which have been made on laser excitation of molecular spectra from powdered solids during the past two years.

A commercial ruby laser with a nominal output of 2.5 joules and a pulse duration of $500 \mu \mathrm{sec}$ has been used in this work. The beam is focused to a $0.5 \mathrm{~mm}$ diameter spot on the surface of the powder sample by an inexpensive microscope objective. The surface power density is thus about 3 MW $\mathrm{cm}^{-2}$. Spectra of the 'flame' produced by the laser beam were recorded photographically in the wave-length range $2000 \AA-7000 \AA$ by Hilger f/4 Raman quartz and constant deviation glass spectrographs. The latter instrument was fitted with a 'Polaroid' camera back in place of its conventional film holder.

The powdered solid target materials used here were superior in performance to non-powdered solids because of their greater surface area, lower reflectivity and lower thermal diffusivity. Since most of the powders have also been shock excited ${ }^{2}$, comparison between the two methods of excitation is possible.

The materials investigated and the gross features of their laser-excited spectra are displayed in Table 1 . In all cases the experiment was porformed in air at atmospheric pressure. As Debras-Guedon and Liodec ${ }^{7}$ have
Table 1. Molecular SPeCtra pRondCed BY LAser Excitation OF

\begin{tabular}{|c|c|c|}
\hline \multirow[b]{2}{*}{ Material } & \multicolumn{2}{|l|}{ POWDERED SOLIDS IN AIR } \\
\hline & Observed molecular spectra* & Remarks \\
\hline Al & $\begin{array}{l}\text { AlO : Blue-Green }\left(\mathrm{A}^{2} \Sigma^{+}-\mathrm{X}^{2} \Sigma^{+}\right) \\
\mathrm{UV}\left(\mathrm{B}^{2} \Pi-\mathrm{X}^{2} \Sigma^{+}\right) \\
\text {AlH : }\left(\mathrm{A}^{1} \Pi-\mathrm{X}^{1} \Sigma\right)\end{array}$ & Very strong \\
\hline $\mathrm{Al}_{2} \mathrm{O}_{3}$ & AlO : Blue-Green $\left(\mathrm{A}^{2} \Sigma^{+}-\mathrm{X}^{2} \Sigma^{+}\right)$ & $\begin{array}{l}\text { Moderate } \\
\text { strength }\end{array}$ \\
\hline B & $\begin{array}{l}\mathrm{BO}:\left(\mathrm{A}^{2} \Pi-\mathrm{X}^{2} \Sigma^{+}\right) \\
\mathrm{BO}_{\mathrm{z}}: \text { Fluctuation bands }\end{array}$ & $\begin{array}{l}\text { Very strong } \\
\text { Very strong }\end{array}$ \\
\hline $13 \mathrm{~N}$ & $\begin{array}{l}\mathrm{BO}:\left(\mathrm{A}^{2} I I-\mathrm{X}^{2} \Sigma^{+}\right) \\
\mathrm{BO}_{\mathrm{a}}: \text { Fluctuation bands }\end{array}$ & No $\mathrm{BN}$ bands \\
\hline $\mathrm{Ba}\left(\mathrm{AlO}_{2}\right)_{\mathrm{a}}$ & $\mathrm{BaO}:\left(\mathrm{A}^{2} \Sigma-\mathrm{X}^{1} \Sigma\right)$ & No Alo bands \\
\hline C & $\begin{array}{l}\mathrm{C}_{\mathrm{a}}: \text { Swan }\left(\mathrm{A}^{3} \Pi_{1}-\mathrm{X}^{\prime 3} \Pi_{u}\right) \\
\text { Deslandres-d'Azambuja }\left(\mathrm{c}^{1} I_{g}-\mathrm{b}^{1} \Pi_{u}\right) \\
\mathrm{CN}: \text { Violet }\left(\mathrm{B}^{2} \Sigma^{+}-\mathrm{X}^{2} \Sigma^{+}\right)\end{array}$ & $\begin{array}{l}\text { Very strong } \\
\text { Very strong } \\
\text { Very strong }\end{array}$ \\
\hline Cas & $\begin{array}{l}\text { "CaO": Orange and Red systems at } 5550 \mathrm{~A} \text { and } \\
6230 \AA\end{array}$ & \\
\hline $\mathrm{CuO}$ & $\begin{array}{l}\mathrm{Cu}_{\mathrm{z}}:\left(\mathrm{B}^{1} \mathrm{II}_{u}-\mathrm{X}^{1} \Sigma_{g}^{+}\right) \\
\mathrm{CuO}: \text { Orange, Violet }\end{array}$ & \\
\hline Cus & $\begin{array}{l}\mathrm{Cu}_{2}:\left(\mathrm{B}^{2} \mathrm{II}_{u}-\mathrm{X}^{1} \Sigma_{g}^{+}\right) \\
\mathrm{CuO}: \text { Orange, violet }\end{array}$ & \\
\hline $\mathrm{Fe}$ & $\mathrm{FeO}: \mathbf{A}, \mathbf{B}$ & \\
\hline $\mathrm{H}_{3} \mathrm{~W}_{4} \mathrm{O}_{8}$ & Wo & \\
\hline $\mathrm{PbS}$ & $\begin{array}{l}\mathrm{PbS}:(\mathrm{A}) \\
\quad \mathrm{AbO}:(\mathrm{A}) ? \mathrm{PbO}:(\mathrm{B})\end{array}$ & $\begin{array}{l}\text { Very weak } \\
\text { Identification } \\
\text { uncertain }\end{array}$ \\
\hline $\mathrm{TiO}_{2}$ & TiO : Red, $\left(A^{3} A-X^{3} I I\right)$, Blue-Green $\left(C^{3} I-X^{3} I\right)$ & $\begin{array}{l}\text { Strong bands, } \\
\text { many } \\
\text { atomic lines }\end{array}$ \\
\hline $\mathrm{V}_{2} \mathrm{O}_{5}$ & VO $:\left({ }^{2} \Delta-{ }^{2} \Delta(?)\right)$ & $\begin{array}{l}\text { Many atomic } \\
\text { lines }\end{array}$ \\
\hline
\end{tabular}

W Wo

* Spectra cited in the same manner as by Pearse and Gaydon?.

discussed laser-excitation of atomic spectra, the atomic features of our spectra are not listed in Table 1. All spectra were relatively free from overlapping continuum. No molecular spectra were observed when $\mathrm{BeO}, \mathrm{Bi}, \mathrm{Cd}, \mathrm{Mg}$, $\mathrm{MgO}, \mathrm{Pb}$, and $\mathrm{S}$ respectively were used as targets for the focused laser beam.

The strong preponderance of oxide band systems observed is consistent with the oxidizing atmosphere in which they were excited and supports the belief that much of the molecular spectrum arises from chemical reactions in the flame. This view is also supported by the work of Howe ${ }^{8}$, who observed that the $\mathrm{C}_{2}$ emission from laser-excited carbon begins promptly with onset of the laser pulse, while the accompanying CN emission is delayed by $15 \mu$ sec. It is interesting to note that the white powders, $\mathrm{BN}$, $\mathrm{TiO}_{2}$, CaS, give rise to laser-excited spectra while some black powders, $\mathrm{Si}, \mathrm{PbS}$, do not.

Intensity measurements are now being made on the molecular spectra to determine vibrational and rotational temperatures. Time-resolved investigations are also being made.

We thank Dr. B. Stoicheff for helpful discussions. The work is supported by grants from the Air Force Office of Scientific Research $(A F-A F O S R$ 62-236A) and from the National Aeronautics and Space Administration (NSG $349)$.

\section{H. I. S. FErguson \\ J. E. Mentali}

R. W. NICHOLLS *

Department of Physics,

University of Western Ontario, London, Ontario.

* Visiting professor, Stanford University.

${ }^{1}$ Nicholls, R. W., and Parkinson, W. H., J. Chem. Phys., 26, 423 (1957).

${ }^{2}$ Nicholls, R. W., Parkinson, W. H., and Reeves, E. M., App. Optics, 2, 919 (1963)

${ }^{3}$ Nelson, L. S., and Kuebler, N. A., Fifth Intern. Symp. Free Radicals (Gordon and Breach Inc., New York, 1961).

${ }^{4}$ Bass, A. M., Kuebler, N. A., and Nelson, L. S., J. Chem. Phys., 40, $312 \mathrm{~L}$ (1964).

5 Koehler, R. A., M.Sc, thesis, Univ. Western Ontario (1965).

B Stoicheff, B. P., Proc. Tenth Coll. Spectroscopium Intern., edit. by Lippincott, E. R., and Margoshes, N. (Spartan Books, Washington, D.C., 1963).

' Debras-Guedon, J., and Liodec, J., C.R. Acad. Sci., Paris, 257, 3336 (1963).

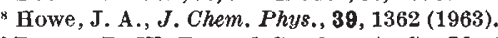

Pearse, R. W. B., and Gaydon, A. G., Identification of Molecular Spectra, third ed. (Chapman and Hall, London, 1963). 